\title{
Analisis Kinerja Penukar Kalor Tipe Shell and Tube untuk Pendinginan Governor
}

\author{
Markus ${ }^{1}$, Yogi Nugroho Bakti ${ }^{2}$ \\ ${ }^{1}$ Jurusan Teknik Refrigerasi dan Tata Udara, Politeknik Negeri Bandung \\ ${ }^{2}$ Jurusan Teknik Mesin, Sekolah Tinggi Teknologi Mandala Bandung \\ Email: ${ }^{1}$ mks_ra@polban.ac.id, ${ }^{2}$ yoginb@sttmanbandung.ac.id
}

\begin{abstract}
ABSTRAK
Salah satu unsur yang mempengaruhi kehandalan dan umur pakai pompa hidrolik (hydraulic pump) adalah tingkat kestabilan kekentalan minyak (oil) sebagai penerus daya. Kestabilan tingkat kekentalan (viscosity) oli dipengaruhi oleh perubahan temperatur. Proses kompresi dan gesekan yang diterima oli untuk menggerakkan pompa hidrolik akan menaikkan temperatur oli sehingga tingkat kekentalannya akan berkurang. Temperatur kerja oli pompa hidrolik harus tetap dipertahankan pada temperature kamar agar kinerja pompa hidrolik dapat dipertahankan. Pada studi kasus di PLTA Ir. H. Djuanda, Jl. Lurah Kawi No.1 Jatiluhur-Jawa Barat, untuk mendinginkan oli digunakan penukar kalor (heat exchanger) jenis shell and tube tipe JPK 13699068 single tube. Penelitian ini dilakukan untuk menguji alat penukar kalor apakah masih bekerja dengan baik, parameternya adalah temperatur keluar oli hasil pendinginan harus mendekati temperatur kamar. Efektifitas penukar kalor akan diuji dengan cara membandingkan hasil pengujian dengan kondisi alat penukar kalor tanpa faktor pengotor. Pengujian dilakukan dengan mengukur temperatur oli masuk HX pada $44{ }^{\circ} \mathrm{C}$ dengan debit $0.437 \mathrm{~kg} / \mathrm{s}$, dan temperatur air masuk HX pada $28{ }^{\circ} \mathrm{C}$ dengan debit $0.498 \mathrm{~kg} / \mathrm{s}$. Hasil penelitian menunjukkan, untuk harga koefisien $U$ antara 110 hingga $350 \mathrm{~W} / \mathrm{m}^{2}{ }^{\circ} \mathrm{C}$ dengan faktor pengotor air $0.0001 \mathrm{~m}^{2}{ }^{\circ} \mathrm{C} / \mathrm{W}$ dan faktor pengotor oli $0.0002 \mathrm{~m}^{2}{ }^{\circ} \mathrm{C} / \mathrm{W}$, terjadi penurunan efektivitas dari rata-rata $74.5 \%$ menjadi $73.7 \%$, serta terjadi kenaikan suhu oli keluar penukar kalor dari rata $32.07{ }^{\circ} \mathrm{C}$ menjadi rata $32.21{ }^{\circ} \mathrm{C}$.
\end{abstract}

Kata kunci: Hydraulic Pump, Viscosity, Penukar Kalor, Efektivitas, Shell and Tube.

\begin{abstract}
One of the elements that affect the reliability and service life of a hydraulic pump is the stability level of oil viscosity as a power successor. The stability level of oil viscosity is affected by changes in temperature. The compression and friction process that the oil receives to move the hydraulic pump will increase the oil temperature so that its viscosity level will decrease. To maintain the performance of the hydraulic pump, the oil temperature must be maintained at room temperature. In the case study at PLTA Ir. H. Djuanda, Lurah Kawi Street No.1 Jatiluhur-West Java, to cool the oil, a shell and tube heat exchanger type JPK 13699068 (single tube) is used. This research was conducted to test whether the heat exchanger is still working properly, the parameter is that the cooled oil exit temperature must be close to room temperature. The effectiveness of the heat exchanger will be tested by comparing the test results with the condition of the heat exchanger without impurity factors. The test was carried out by measuring the temperature of the HX intake oil at $44^{\circ} \mathrm{C}$ with a discharge of $0.437 \mathrm{~kg} / \mathrm{s}$, and the temperature of the HX inlet water at $28{ }^{\circ} \mathrm{C}$ with a discharge of $0.498 \mathrm{~kg} / \mathrm{s}$. The results showed that, for the coefficient of U between 110 to $350 \mathrm{~W} / \mathrm{m}^{2{ }^{\circ}} \mathrm{C}$ with a water impurity factor of $0.0001 \mathrm{~m}^{20} \mathrm{C} / \mathrm{W}$ and an oil impurity factor of $0.0002 \mathrm{~m}^{2 \circ} \mathrm{C} / \mathrm{W}$, there was a decrease in effectiveness from an average of $74.5 \%$ to $73.7 \%$, and there was an increase in oil temperature out of the heat exchanger from an average of $32.07^{\circ} \mathrm{C}$ to an average of $32.21{ }^{\circ} \mathrm{C}$.
\end{abstract}

Keywords: Hydraulic Pump, Viscosity, Heat Exchangers, Effectiveness, Shell and Tube. 


\section{Pendahuluan}

Pompa hidrolik merupakan alat utama pada sistem pemesinan, sehingga kinerjanya harus dipertahankan dengan optimal. Perawatan yang tidak optimal pada komponen pendukung kerja pompa hidrolik (penukar kalor) akan menurunkan kinerja sistem pemesinan, disamping itu akan menurunkan umur pakai sistem pemesinan secara keseluruhan.

Setelah alat penukar kalor digunakan beberapa waktu, permukaan alat penukar kalor (heat exchanger) akan mengalami endapan yang terdapat dalam sistem aliran, atau permukaan perpindahan kalor mengalami korosi sebagai akibat interaksi antara fluida dengan bahan yang digunakan untuk konstruksi penukar kalor. Pada kondisi di atas, endapan atau korosi akan memberikan tahanan termal (panas) terhadap aliran kalor, sehingga akan menurunkan kinerja alat penukar kalor [1]. Untuk mengurangi dan meminimalisir endapan atau korosi material, maka fluida harus bebas dari pengotor, dan harus dihindari penggunaan material yang mudah korosif. Perawatan secara berkala tetap harus dilakukan secara teratur dan terencana. Penelitian dilakukan karena adanya penurunan kinerja alat penukar kalor yang ditunjukkan oleh cukup tingginya temperatur oli pompa hidrolik keluar dari alat penukar kalor.

\subsection{Penukar Kalor Shell and Tube}

Jenis penukar kalor shell and tube, dimana salah satu fluida mengalir di dalam rangkuman tabung dan fluida yang lain mengalir menyilang luar-tabung. Untuk menjamin laju perpindahan kalor optimal maka di dalam shell (cangkang/rumah) dipasang sekat-sekat (baffles) [2].

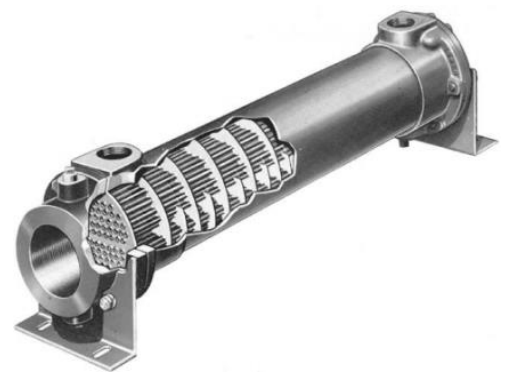

Gambar 1. Penukar kalor shell and tube [2]

Untuk jenis penukar kalor yang bukan jenis pipa-ganda (double-pipe heat exchanger), laju perpindahan kalor dapat dihitung menggunakan persamaan untuk penukar kalor pipa-ganda aliran lawan-arah dengan memasukkan faktor koreksi terhadap beda temperatur rata-rata logaritma (log mean temperature difference). Bentuk persamaan perpindahan kalor adalah:

$$
q: U . A . F . \Delta T_{L M T D}
$$

dimana:

$q \quad:$ laju perpindahan kalor $(W)$

$U \quad$ : koefisien perpindahan kalor menyeluruh $\left(\mathrm{W} / \mathrm{m}^{2}{ }^{\circ} \mathrm{C}\right)$

A : luas permukaan perpindahan kalor $\left(\mathrm{m}^{2}\right)$

$F \quad$ : faktor koreksi

$\Delta T_{L M T D}:$ beda temperature rata-rata logaritma $\left({ }^{\circ} \mathrm{C}\right)$

\subsection{Beda Suhu Rata-rata Log.}

Gambar 2 menunjukkan jenis penukar kalor pipa-ganda aliran-lawan-arah, dan gambar 3 menunjukkan karakteristik temperatur terhadap luas permukaan perpindahan kalor aliran-lawanarah.

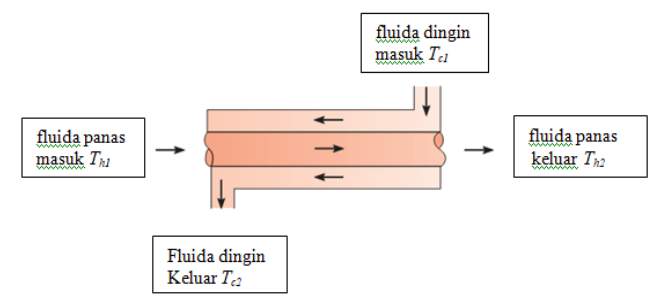

Gambar 2. Penukar kalor pipa-ganda aliranlawan-arah [2]

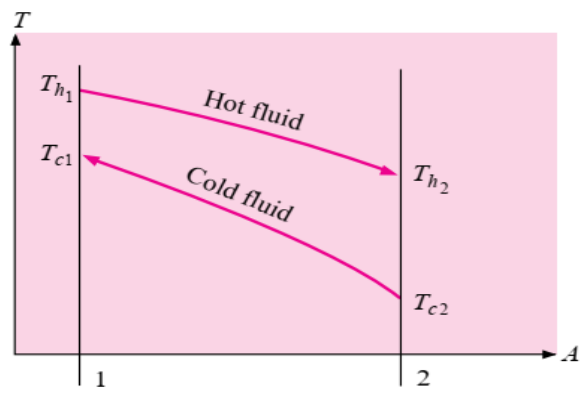

Gambar 3. Karakteristik temperatur terhadap luas permukaan perpindahan kalor aliran-lawan-arah [2]

Laju perpindahan panas dapat juga dihitung menggunakan persamaan kesetimbangan energi termal, yaitu kalor yang dilepas fluida panas sama dengan kalor yang diserap fluida dingin.

$q=\dot{m}_{h} c_{p h} T_{h}=\dot{m}_{c} c_{p c} T_{c}$ 
dimana :

$\dot{m}$ : laju aliran massa fluida $(\mathrm{m} / \mathrm{s})$

$c_{p}$ : kalor jenis fluida $\left(\mathrm{kJ} / \mathrm{kg}^{\circ} \mathrm{C}\right)$

subskrip h dan $\mathrm{c}$ menunjukkan fluida panas dan dingin

Dengan substitusi hubungan antara persamaan (1) dan (2), didapat persamaan beda temperatur rata-rata logaritma sebagai berikut [1]-[3],

$$
(\Delta T)_{L M T D}=\frac{\left(T_{h 2}-T_{c 2}\right)-\left(T_{h 1}-T_{c 1}\right)}{\ln \frac{\left(T_{h 2}-T_{c 2}\right)}{\left(T_{h 1}-T_{c 1}\right)}}
$$

\subsection{Koefisien Perpindahan Kalor Menyeluruh} $(\boldsymbol{U})$

Koefisien $U$ menunjukkan nilai tahanan termal yang harus dilalui kalor dari fluida panas ke fluida dingin. Tahanan termal menyeluruh merupakan penjumlahan tahanan termal fluida panas, tahanan termal endapan (pengotor) pipa fluida panas, tahanan termal dinding pipa (pemisah fluida panas dan dingin), tahanan termal endapan pipa fluida dingin, dan tahanan termal fluida dingin; nilai koefisien $U$ dinyatakan dengan persamaan (4),

$\frac{1}{U A}=\frac{1}{U_{i} A_{i}}=\frac{1}{U_{O} A_{O}}=\frac{1}{h_{i} A_{i}}+\frac{R_{f i}^{\prime \prime}}{h_{i} A_{i}}+\frac{\ln \left(D_{o} / D_{i}\right)}{2 \pi k L}+$

$\frac{R_{f o}^{\prime \prime}}{h_{o} A_{o}}+\frac{1}{h_{o} A_{o}}$

dimana:

$R_{f i}^{\prime \prime}$ : faktor pengotor (endapan/korosi) $\left(m^{2} K / W\right)$

$h$ : koef. konveksi fluida $\left(W / m^{2} K\right)$

$k$ : koef. konduksi pipa $(W / m K)$

$L \quad$ : panjang pipa $(m)$

$D$ : diameter pipa $(m)$

Subskrip $i$ dan $o$ menunjukkan pipa sisi-dalam dan pipa sisi-luar.

\subsection{Faktor Koreksi $(F)$}

Beda suhu rata-rata logaritma hanya berlaku untuk penukar kalor pipa ganda aliran searah dan lawan arah. Untuk penukar kalor jenis yang lain dapat pula menggunakan $\triangle T_{L M T D}$ dengan memasukkan factor koreksi $(F)$. Nilai faktor koreksi dapat dihitung menggunakan gambar 4 berikut,

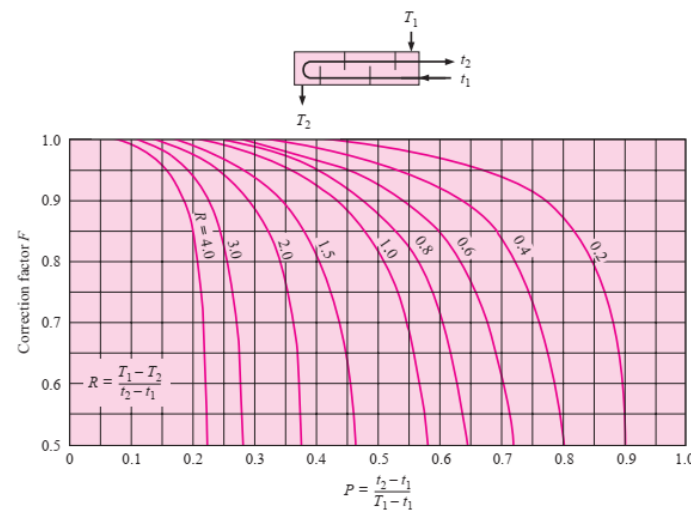

Gambar 4. Grafik faktor koreksi untuk penukar kalor shell and tube,satu lintas cangkang dan multi lintas tabung [2]

Bila terjadi perubahan fasa pada fluida seperti pendidihan (penguapan), dan kondensasi (pengembunan), pada hakikatnya temperature fluida tetap, sehingga didapat nilai $\mathrm{P}$ atau $\mathrm{R}$ sama dengan 0 (nol), dan apabila diplotkan pada gambar grafik di atas maka diperoleh nilai $F$ sama dengan satu.

\subsection{Metode Efektivitas-NTU}

Efektivitas penukar kalor dinyatakan sebagai rasio laju perpindahan kalor nyata terhadap laju perpindahan kalor maksimum yang mungkin $[1,2,3]$. Laju perpindahan kalor nyata dapat diperoleh dari fluida panas atau fluida dingin.

$\varepsilon=\frac{\text { laju perpindahan kalor nyata }}{\text { laju perpindahan kalor maksimum yang mungkin }}$

Laju perpindahan kalor nyata untuk fluida panas dan dingin dinyatakan dengan persamaan :

$q_{h}=\dot{m}_{h} c_{p h}\left(\Delta T_{h}\right)$ atau

$q_{c}=\dot{m}_{c} c_{p c}\left(\Delta T_{c}\right)$

Untuk penukar kalor aliran lawan arah (gambar 2 dan 3), diperoleh persamaan kesetimbangan energi antara fluida panas dan fluida dingin sebagai berikut,

$$
\begin{aligned}
q & =\dot{m}_{h} c_{p h}\left(T_{h 1}-T_{h 2}\right) \\
& =\dot{m}_{c} c_{p c}\left(T_{c 1}-T_{c 2}\right)
\end{aligned}
$$

Laju perpindahan kalor maksimum yang mungkin diperoleh dari hasil perkalian antara beda suhu maksimum pada alat penukar kalor dengan $\left(\dot{m} c_{p}\right)$ minimum, atau :

$q=\left(\dot{m} c_{p}\right)_{\text {min }}\left(T_{h, i n}-T_{c, i n}\right)$ 
Sehingga efektivitas dapat dinyatakan sebagai :

Efektivitas ( $(\varepsilon)$ :

$$
\begin{gathered}
\begin{array}{c}
\text { beda suhu fluida dengan nilai } \\
(\mathrm{m} \text { cp }) \text { minimum }
\end{array} \\
\frac{\begin{array}{c}
\text { beda suhu fluida panas masuk dengan } \\
\text { suhu fluida dingin masuk }
\end{array}}{\varepsilon: \frac{(\Delta T)_{\mathrm{Cmin}}}{(\Delta T)_{\operatorname{mak}}}} \\
c_{\text {min }}:\left(\dot{m} c_{p}\right)_{\min }
\end{gathered}
$$

$(\Delta T)_{m a k}: T_{h, i n}-T_{c, i n}$

Untuk penukar kalor shell and tube aliran silang; satu lintas shell dan multi lintas tube; $c_{m a k}$ tidak campur dan $c_{\min }$ campur, efektivita penukar kalor dihitung menggunakan persamaan,

$\varepsilon=1-\exp \left\{-\left(\frac{1}{C}\right)[1-\exp (-N C)]\right\}$

dimana :

$C={ }^{c_{\text {min }}} / c_{\text {mak }}$

$N=U A / c_{\text {min }}$

Hasil penelitian pendinginan bahan bakar menggunakan udara blower menghasilkan efektivitas sebesar $14 \%$ [4]. Sedangkan hasil penelitian penukar kalor dengan menaikkan laju aliran volume fluida pendingin akan meningkatkan efektivitas penukar kalor [5]. Pengotor/endapan (fouling) pada alat penukar kalor akan menyebabkan tambahan biaya bagi sektor industri [6]. Tambahan biaya tersebut dalam bentuk peningkatan biaya pokok pembuatan (fabrikasi), peningkatan biaya pemeliharaan (maintenance), kerugian produksi, dan kerugian energi. Sedangkan peningkatan fouling faktor akan menurunkan koefisien $U$ [7].

Hasil penelitian dengan membandingkan penukar kalor pipa ganda tanpa modifikasi dengan yang telah dimodifikasi dengan penambahan silinder pejal pada sisi tube, terjadi peningkatan efektivitas dari $48.46 \%$ menjadi $78.8 \%$ [8]. Sedangkan hasil penelitian dengan mamanfaatkan panas gas buang untuk memanaskan air menggunaka shell and tube dengan program heat transfer research inc (HTRI) didapat efektivitas sebesar $51 \%$ dengan fouling faktor $0.00289{ }^{\circ} \mathrm{C} \mathrm{m} / \mathrm{W}$ [9]. Hasil dari rancangan penukar kalor untuk kafasitas 5100 Watt, didapat efektivitas sebesar $62 \%$ [11].

Hasil penelitian dengan membandingkan kinerja penukar kalor tipe plate frame dengan penukar kalor shell and tube, didapat efektivitas $30 \%$ untuk tipe plate frame, dan $45.6 \%$ untuk shell and tube [12]. Sedangkan penelitian menggunakan penukar kanlor shell and tube dengan mengatur suhu outlet, didapat laju perpindahan panas hingga $83.17 \mathrm{~kW}$ dengan efektivitas minimum $77 \%$ [13]. Pada penelitian untuk menganalisis kinerja shell and tube menggunakan metode CFD dan Kern method; dengan metode $C F D$ didapat hasil: suhu air masuk $30{ }^{\circ} \mathrm{C}$ dan keluar $31{ }^{\circ} \mathrm{C}$, suhu oli masuk 55 ${ }^{\circ} \mathrm{C}$ dan kelur $53{ }^{\circ} \mathrm{C}$; sedangkan dengan metode Kern method didapat hasil: suhu air masuk $30{ }^{\circ} \mathrm{C}$ dan keluar $31{ }^{\circ} \mathrm{C}$, suhu oli masuk $55{ }^{\circ} \mathrm{C}$ dan keluar $52{ }^{\circ} \mathrm{C}[14]$.

\section{Metode Penelitian}

Penelitian dilakukan di PLTA (pusat listrik tenaga air) Jatiluhur Bandung Jawa Barat. Alat yang diteliti berupa penukar kalor (heat exchanger) yang berfungsi untuk mendinginkan oli pompa hidrolik. Penelitian bertujuan untuk mengetahui efektivitas penukar kalor setelah cukup lama dioperasikan. Fluida pendingin menggunakan air yang masuk penukar kalor pada temperatur $28{ }^{0} \mathrm{C}$ dengan debit $0.498 \mathrm{~kg} / \mathrm{s}$, sedangkan oli masuk penukar kalor pada temperatur $44{ }^{0} \mathrm{C}$ dengan debit $0.437 \mathrm{~kg} / \mathrm{s}$. Penukar kalor yang diteliti adalah jenis shell and tube, air mengalir di dalam tube sedangkan oli mengalir di dalam shell.

\subsection{Lingkup dan Tahap Penelitian}

Lingkup dan tahap penelitian perlu disusun agar penelitian dapat fokus pada tujuan yang mau dicapai. Penelitian melingkupi hal-hal pokok berikut ini:

1. Menentukan topik penelitian yang akan dilakukan, dengan mencari referensi text book, jurnal, dan artikel yang relevan.

2. Menguraikan teori, jurnal hasil penelitian, dan artikel yang mendukung topik penelitian.

3. Menentukan komponen pendukung untuk mendapatkan data uji yang mendukung tujuan penelitian.

4. Mengolah data dan menganalisis untuk mendapatkan hasil dan kesimpulan.

\subsection{Alur Penelitian}

Alur penelitian digambarkan pada diagram tulang ikan berikut ini: 


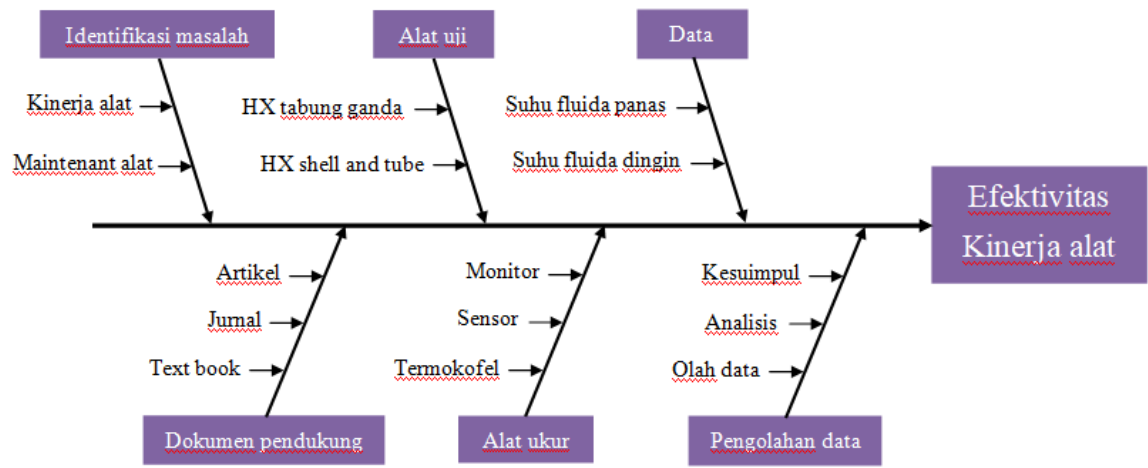

Gambar 5. Diagram tulang ikan alur penelitian

\subsection{Pentahapan Penelitian}

Pentahapan penelitian digambarkan pada gambar 6 berikut ini:
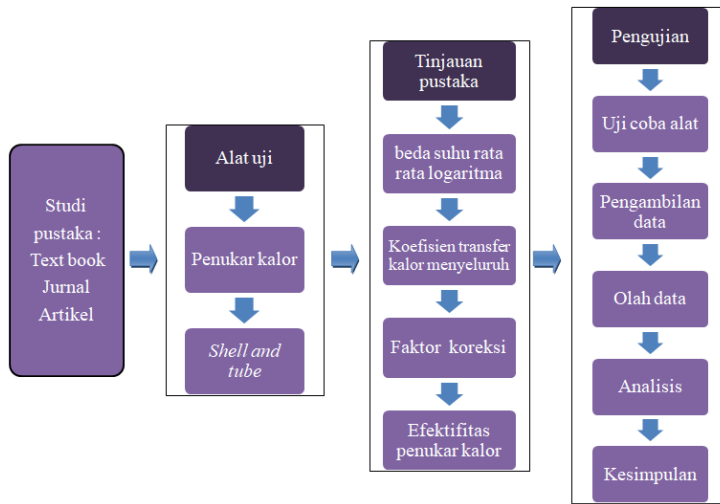

Gambar 6. Tahapan penelitian

\subsection{Alat uji}

Penelitian menggunakan penukar kalor shell and tube tipe JPK 13699068 single tube yang berfungsi untuk mendinginkan oli pompa hidrolik menggunakan air sebagai pendingin. Pengambilan data dilakukan di PLTA (pusat listrik tenaga air) Ir. H. Djuanda Jatiluhur Bandung. Untuk mengetahui kinerja penukar kalor akibat pengotor (fouling) diasumsikan tahanan pengotor $\left(R_{f, i}\right)$ pada sisi air sebesar $0.0001{ }^{\circ} \mathrm{C} \mathrm{m}^{2} / \mathrm{W}$ dan pada sisi oli $\left(R_{f, o}\right)$ sebesar $0.0002{ }^{\circ} \mathrm{C} \mathrm{m}^{2} / \mathrm{W}$ [1], [2].

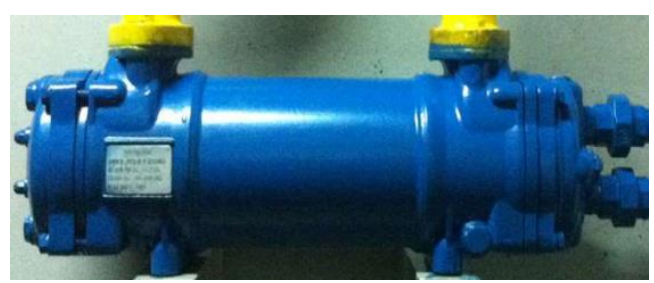

Gambar 7. Penukar kalor shell and tube tipe JPK 13699068 single tube

Dimensi shell and tube tipe JPK 13699068 adalah, panjang $1.65 \mathrm{~m}$, diameter shell $25 \mathrm{~cm}$, diameter tube 1/4 inch, dan jumlah tube 353.

\section{Hasil dan Pembahasan}

Data uji yang diukur dan diperoleh dari sifatsifat fluida air dan oli adalah: Suhu oli masuk HX = $44{ }^{\circ} \mathrm{C}$, suhu air masuk $\mathrm{HX}=28{ }^{\circ} \mathrm{C}$, debit oli $=$ $0.437 \mathrm{~kg} / \mathrm{s}$, debit air $=498 \mathrm{~kg} / \mathrm{s}$, kalor jenis oli $=$ $1980.8 \mathrm{~J} / \mathrm{kg}{ }^{\circ} \mathrm{C}$, dan kalor jenis air $=4178.8 \mathrm{~J} / \mathrm{kg}{ }^{\circ} \mathrm{C}$. Sedangkan koefisien perpindahan kalor menyeluruh $U$ diasumsikan bernilai antara $110 \mathrm{~W} / \mathrm{m}^{2}{ }^{\circ} \mathrm{C}$ hingga $350 \mathrm{~W} / \mathrm{m}^{2}{ }^{\circ} \mathrm{C}$ [1], [2].

Dari pengolahan data, diperoleh hasil sebagai berikut: gambar 8 menunjukkan karakteristik penurunan suhu oli di dalam penukar kalor, dimana penukar kalor masih berfungsi dengan baik, yang ditunjukkan oleh suhu oli keluar HX masih memenuhi standar kerja yang diberikan. Adanya fouling tidak terlalu berpengaruh pada suhu oli keluar, dan hanya terjadi kenaikan rata-rata $0.44 \%$

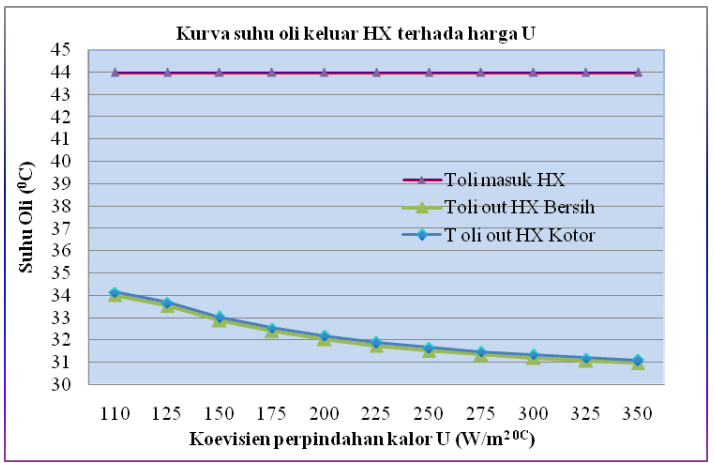

Gambar 8. Kurva suhu oli keluar penukar kalor terhadap $U$

Gambar 9 menunjukkan karakteristik laju perpindahan kalor terhadap $U$. Untuk harga $U$ minimum dengan laju perpindahan kalor sebesar $8.53 \mathrm{~kW}$ terjadi kenaikan temperatur oli keluar maksimum pada suhu $34.16{ }^{\circ} \mathrm{C}$. Dengan pengaruh fouling, laju perpindahan kalor mengalami penurunan rata-rata $1.2 \%$. 


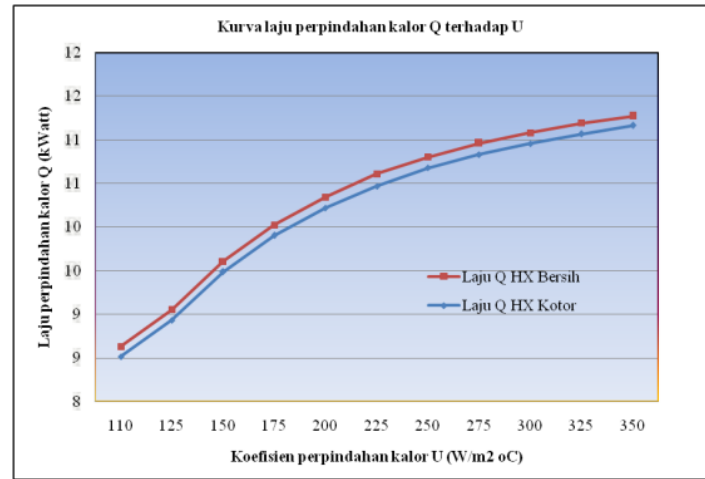

Gambar 9. Kurva laju perpindahan kalor $Q$ terhadap $\boldsymbol{U}$

Gambar 10 menunjukkan karakteristik efektivitas penukar kalor. Hasil penelitian menunjukkan efektivitas minimum adalah $61.5 \%$ dan maksimum $80.6 \%$, dengan efektivitas rat-rata $73.7 \%$. Pengaruh fouling hanya menurunkan efektivitas rata-rata $1.2 \%$. Hasil penelitian menunjukkan bahwa kinerja alat penukar kalor masih memenuhi kriteria yang disyaratkan oleh perusahaan, yang ditunjukkan oleh suhu oli keluar maksimum $34.16{ }^{\circ} \mathrm{C}$.

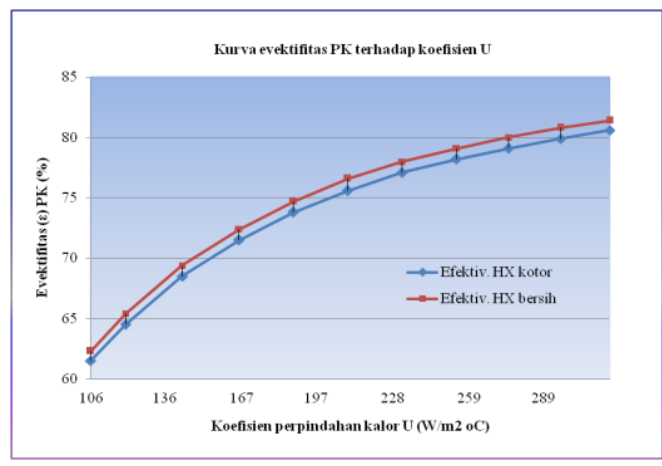

Gambar 10. Kurva efektivitas penukar kalor $\mathcal{E}$ terhadap $U$

Hasil penelitian ini lebih baik bila dibandingkan dengan penelitian lain yang memanfaatkan gas buang panas untuk memanaskan air pengisi boiler menggunakan alat penukar kalor shell and tube yang menghasilkan efektivitas $51 \%$ dengan faktor pengotor 0.00289 ${ }^{0} \mathrm{C} \mathrm{m}^{2} / \mathrm{W}$ [9].

\section{Kesimpulan}

Dari hasil penelitian dapat disimpulkan bahwa:

Untuk harga $U$ antara $110 \mathrm{~W} / \mathrm{m}^{2}{ }^{\circ} \mathrm{C}$ hingga $350 \mathrm{~W} / \mathrm{m}^{2}{ }^{\circ} \mathrm{C}$ dan tanpa pengotor, penukar kalor memiliki efektivitas rata-rata $74.5 \%$. Sedangkan dengan asumsi nilai faktor pengotor pada sisi air sebesar $0.0001{ }^{\circ} \mathrm{C} \mathrm{m}^{2} / \mathrm{W}$ dan pada sisi oli $\left(R_{f, o}\right)$ sebesar $0.0002{ }^{\circ} \mathrm{C} \mathrm{m}^{2} / \mathrm{W}$, diperoleh efektivitas penukar kalor rata-rata $73.7 \%$.

Temperatur oli mengalami penurunan dari 44 ${ }^{\circ} \mathrm{C}$ menjadi rata-rata $32.21{ }^{\circ} \mathrm{C}$ dengan temperatur air pendingin masuk pada $28^{\circ} \mathrm{C}$.

Dari hasil penelitian dapat saran bahwa untuk mengantisifasi meningkatnya fouling factor, luas permukaan perpindahan kalor harus diperbesar, dan untuk mengkompensasi penambahan luas permukaan perpindahan kalor maka kapasitas pompa harus ditambah [6].

\section{Daftar Pustaka}

[1] Yunus A. Cengel, Afshin J. Ghajar, Heat and Mass Transfer: Fundamentals and Applications, McGraw-Hil. McGraw-Hill Education, 2015.

[2] J.P Holman, Heat Transfer, Tenth Edit. Mc GrawHill Companies, Inc, 2010.

[3] Theodore L. Bergman, Adrienne S. Lavine, Fundamentals of Heat and Mass Transfer, Eighth Edi. John Wiley \& Sons, Inc., 2017.

[4] Sulaiman, Nofitra Satria "Analisis efektivitas Alat Penukar Kalor," J. Tek. Mesin, vol. 4 No.1, pp. 2224, 2014

[5] Markus, Faldian, "Analysis of Double Pipe Heat Exchanger Performance by Utilizing the Heat of Discharge Compressor pipe," Pros. Semin. Nas. Edusainstek UNIMUS, pp. 155-162, 2019.

[6] Yopi Handoyo, Ahsan, "Analisis Kinerja Alat Penukar Kalor Jenis Shell and Tube Pendingin Aliran Air pada PLTA Jatiluhur," J. Energi dan Manufaktur, vol. 5 No.1, pp. 42-50, 2012.

[7] Yasir Amani, "Predict Tube Overal Foulingin Heat Exchanger 53 EA-1001," J. Sist. Inf., vol. 2 No.1, pp. 95-109, 2018.

[8] Indra Pertama Putra, Kennedy M, dan Basri, "Pengaruh Penambahan Silinder Pejal pada Alat Penukar Kalor Pipa Ganda,” J. Mek., vol. 9 No. 1, pp. 800-807, 2018.

[9] Marno dan Awal Nurahmadi, "Kajian Alat Penukar Kalor Shell and Tube Menggunakan Program Heat Transfer Research Inc (HTRI)," Barom. J. Ilmu dan Apl. Tek., vol. 2 No.1, pp. 12-18, 2017.

[10] Jim Barbee dkk, Standards of The Tubular Exchanger Manufacturers Association (TEMA), Ninth Edit. 2007.

[11] Saut Siagian, "Analisis Efektivitas Alat Penukar Kalor Jenis Shell and Tube Hasil Rancangan Mahasiswa Skala Laboratorium," Bina Tek., vol. 12 No.2, pp. 211-216. 
[12] Shilfa Maharani, Belyamin, dan Arifia Ekayuliana, "Kajian Kinerja Penukar Panas Tipe Shell and Tube Satu Haluan dengan Pengontrolan Suhu Outlet," J. Rekayasa Kim. dan Lingkung., vol. 9 No.4, pp. 129-137, 2019.

[13] Hendri Syah, "Kajian Kinerja Penukar Panas Tipe Shell and Tube Satu Haluan dengan Pengontrolan
Suhu Outlet," J. Rekayasa Kim. dan Lingkung., vol. Vol. 9 No., pp. 158-165, 2013.

[14] Candra D W, Gun Gun R G, dan Adi Syuriadi, "Pemodelan dan Analisis Kinerja Shell and Tube Heat Exchanger dengan Metode CFD," $J$. Politeknologi, vol. 16 No.3, pp. 239-243, 2017. 